\title{
ARMAZENAMENTO DE SOJA EM SILOS TIPO BOLSA
}

\section{LÊDA R. A. FARONI ${ }^{1}$, ERNANDES R. DE ALENCAR ${ }^{2}$, JULIANA L. PAES ${ }^{3}$, ANDRÉ R. DA COSTA ${ }^{4}$, RAFAELA C. C. ROMA ${ }^{5}$}

RESUMO: Avaliaram-se as principais alterações qualitativas de soja armazenada em silos tipo bolsa e do óleo bruto extraído de soja com teores de água de 17,4\% e 13,3\%, armazenada em dois silos tipo bolsa, por 180 dias. Realizaram-se amostragens no dia do enchimento das bolsas, aos 30; 90 e 180 dias de armazenamento. Analisaram-se o teor de água, a condutividade elétrica, o percentual de germinação, a massa específica aparente da soja, além do teor de ácidos graxos livres e o índice de peróxido do óleo bruto extraído dela. Os teores de água da soja armazenada úmida e seca mantiveram-se próximos dos valores obtidos no início do período de armazenamento. Observou-se tendência de elevação da condutividade elétrica e decréscimo do percentual de germinação somente na soja úmida, principalmente após 90 dias de armazenamento. Não foi verificado decréscimo da massa específica aparente do material armazenado úmido e seco. Com relação aos parâmetros qualitativos do óleo bruto, observou-se que os valores obtidos se mantiveram abaixo do limite máximo exigido pela legislação para a comercialização de óleo bruto de soja. Pode-se concluir que os silos tipo bolsa representam alternativa viável do ponto de vista qualitativo para armazenagem de soja, e esse tipo de estrutura não ocasiona alterações qualitativas significativas no óleo bruto obtido desse material, em condições similares àquelas deste estudo.

PALAVRAS-CHAVE: armazenamento hermético, qualidade, óleo bruto.

\section{SOYBEAN STORAGE IN BAG TYPE SILOS}

\begin{abstract}
This study reports major qualitative changes in the soybean grains and the extracted crude oil when stored in bag type silos. Grains with moisture content of 17.4 or $13.3 \%$ were stored in two bag type silos. Samples were taken 30, 90 and 180 days of storage, to determine moisture content, electric conductivity of the grain leachate, germination percentage, apparent specific grain mass, and free fatty acid content, and peroxide index of the crude oil extracted from these grains. The wet and dry grains remained with moisture contents similar to the original levels during the storage period. There was a tendency for to increase in the electric conductivity and decrease in the germination percentage of moist soybeans, especially after a ninety-day storage. The apparent grain density of moist or dry soybeans did not decrease. As regarding to the qualitative parameters of crude oil, the values remained below the legal limits required for marketing crude soybean oil. From the results it can be concluded that bag type silos represent a viable alternative for soybean storage without quality loss, and also storage in such structures does not lead to qualitative changes in the crude oil obtained from such grains.
\end{abstract}

KEYWORDS: hermetic storage, grain quality, crude oil.

\footnotetext{
${ }^{1}$ Profa. Associada, Departamento de Engenharia Agrícola, Universidade Federal de Viçosa, Viçosa - MG, Fone: (0XX31) 38991874, lfaroni@ufv.br

${ }^{2}$ Doutorando em Engenharia Agrícola, Departamento de Engenharia Agrícola, UFV, Viçosa - MG, eg40942@ vicosa.ufv.br

${ }^{3}$ Mestranda em Engenharia Agrícola, Departamento de Engenharia Agrícola, UFV, Viçosa - MG, jlp@ vicosa.ufv.br

${ }^{4}$ Bolsista de Iniciação Científica do CNPq, Departamento de Engenharia Agrícola, UFV, Viçosa - MG, ardcosta@ yahoo.com.br

${ }^{5}$ Bolsista de Iniciação Científica do CNPq, Departamento de Engenharia Agrícola, UFV, Viçosa - MG, faelaromal@ yahoo.com.br Recebido pelo Conselho Editorial em: 1은 -6-2007

Aprovado pelo Conselho Editorial em: 2-3-2009
} 


\section{INTRODUÇÃO}

A produção agrícola brasileira precisa avançar na direção das exigências internacionais para alcançar os mercados externos, uma vez que é essencial a manutenção da qualidade dos grãos durante o armazenamento, a fim de que sejam evitadas perdas econômicas. A qualidade dos grãos é importante parâmetro para a comercialização e o processamento, podendo afetar o valor do produto (COUTO et al., 1998). Apesar de toda a tecnologia disponível à agricultura brasileira, as perdas qualitativas e quantitativas, originadas durante o processo de pós-colheita dos grãos, ainda não são bem controladas, e, durante o armazenamento, a massa de grãos é constantemente submetida a fatores externos.

A utilização de bolsas seladas hermeticamente para o armazenamento de grãos é uma tecnologia que, além de muito utilizada na Argentina, tem merecido estudos por alguns pesquisadores (CASINI et al., 2006; RODRIGUEZ et al., 2004), como alternativa aos métodos tradicionais de armazenagem em fazenda. Essa nova técnica consiste no armazenamento de grãos em bolsas plásticas seladas hermeticamente, em que o processo respiratório dos componentes bióticos do ecossistema (grãos, fungos, insetos) consome o oxigênio $\left(\mathrm{O}_{2}\right)$, gerando dióxido de carbono $\left(\mathrm{CO}_{2}\right)$. Ressalta-se que uma atmosfera rica em $\mathrm{CO}_{2}$ e pobre em $\mathrm{O}_{2}$ pode suprimir a capacidade de reprodução e/ou desenvolvimento dos insetos e fungos, como também a própria atividade metabólica dos grãos, favorecendo a sua conservação (VARNAVA et al., 1995; JAYAS, 2000; MORENO et al., 2006), além de reduzir a taxa de oxidação do produto armazenado (VILLERS et al., 2006).

Os insetos são suprimidos quando o ar intergranular apresenta concentração de oxigênio de $2 \%$ ou menos. Ainda, o desenvolvimento fúngico cessa quando a concentração de oxigênio é de aproximadamente 1\% (MORENO et al., 2000). RUPOLLO et al. (2006) afirmam que, no armazenamento hermético, o $\mathrm{CO}_{2}$ gerado e, consequentemente, a redução do $\mathrm{O}_{2}$ no sistema estabilizam o processo de degradação da massa de grãos pela redução da taxa respiratória dos próprios grãos e dos organismos presentes.

A soja apresenta cerca de $20 \%$ de teor lipídico, que são suscetíveis ao processo de deterioração qualitativa, sob forma de degradação dessas substâncias, quando armazenados de forma inadequada, podendo acarretar sérios prejuízos para a indústria alimentícia. A qualidade do óleo refinado é influenciada pela qualidade do óleo bruto e do material do qual o óleo foi extraído. A armazenagem de soja com teor de água elevado propicia danos à qualidade dos óleos bruto, refinado, branqueado e desodorizado. Análises como a do teor de ácidos graxos livres e do índice de peróxido, dentre outras, são utilizadas para avaliar danos na matéria-prima e na qualidade do óleo extraído (FRANKEL et al., 1987; REGITANO-D'ARCE et al., 1994). A qualidade da soja pode influenciar nos parâmetros qualitativos de outros derivados, como $\mathrm{pH}$, sólidos totais, cor do extrato hidrossolúvel de soja, dureza e rendimento do tofu (NARAYAN et al., 1988; HOU \& CHANG, 2004).

O teor de ácidos graxos livres expressa a quantidade de ácidos graxos liberados da estrutura do glicerol e está associado à rancidez hidrolítica (DHINGRA et al., 1998). Valores elevados significam não apenas maiores perdas no processo de refino, como também qualidade inferior do óleo, que por sua vez indica baixa qualidade da matéria-prima, manejo inadequado ou falta de controle durante o processamento. Por outro lado, o índice de peróxido é a medida da rancidez oxidativa ou ranço em sua fase inicial e mede a concentração de substâncias, em termos de miliequivalentes de peróxidos por mil gramas de amostra, que oxida iodeto de potássio a iodo e é amplamente usado na determinação da qualidade de óleos e gorduras, tendo boa correlação com o sabor (O'BRIEN, 2004). Esse parâmetro é indicador muito sensível no estádio inicial da oxidação, e sua presença é indício de que a deterioração do sabor e odor, em função de sua instabilidade, está por acontecer. Quando sua concentração atinge certo nível, mudanças complexas ocorrem, formando compostos de baixo peso molecular, oriundos de sua degradação. 
Dessa forma, é de suma importância avaliar a qualidade da matéria-prima e do óleo bruto para que seja possível verificar alterações qualitativas da soja armazenada em silos-bolsa, considerando que tal estrutura de armazenamento é relativamente nova nas condições climáticas brasileiras. Em vista do exposto, teve-se o objetivo de, com este trabalho, avaliar as principais alterações qualitativas na soja armazenada em silos-bolsa e do óleo bruto extraído desse material, na região de Guarapuava - PR.

\section{MATERIAL E MÉTODOS}

Soja foi armazenada úmida e seca, com teores iniciais de água de 17,4 e 13,3\%, respectivamente, em silos tipo bolsa (Figura 1), instalados na sede da Cooperativa Agrária, filial Guarapuava - PR, por 180 dias. O material dos silos-bolsa é composto de três camadas de polietileno de alta densidade, com seguintes características: camada externa branca, composta de dióxido de titânio, cuja função é refletir os raios ultravioleta, preservando o plástico e aumentando sua resistência, e duas camadas internas pretas para ajudar a manter a temperatura da massa de grãos.

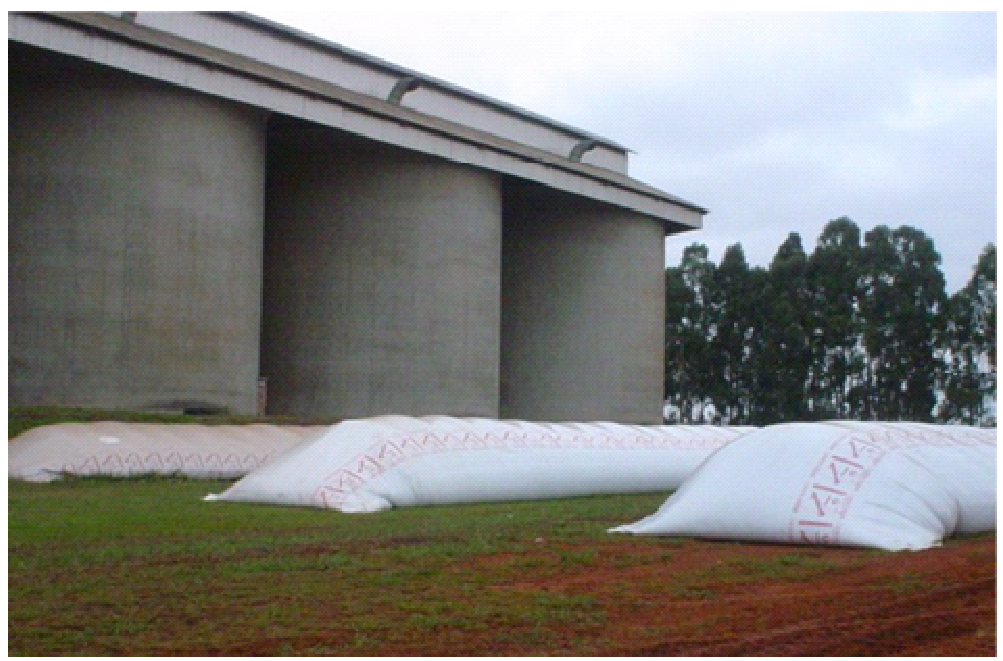

FIGURA 1. Silos tipo bolsa instalados na Cooperativa Agrária, Guarapuava - PR. Bag type silos installed inat Cooperativa Agrária, Guarapuava - PR, Brazil.

Realizaram-se amostragens no dia do enchimento das bolsas, após 30; 90 e 180 dias de armazenamento. Em cada bolsa e após cada intervalo de tempo, foi realizada amostragem em três pontos, a $10 \mathrm{~m}$ do início da bolsa, no meio da bolsa e nos últimos $10 \mathrm{~m}$ da bolsa. Em cada ponto de amostragem, foram retiradas amostras das camadas superior, intermediária e inferior. Em seguida, as amostras eram encaminhadas para o Laboratório de Grãos do Departamento de Engenharia Agrícola, da Universidade Federal de Viçosa - UFV, em Viçosa - MG. Destaca-se que as amostras foram devidamente armazenadas e transportadas até o local de realização das análises de tal modo que não ocorresse deterioração qualitativa do produto.

Realizaram-se as seguintes análises:

Teor de água: para a determinação do teor de água dos grãos de soja, utilizou-se do método de estufa, à temperatura de $103 \pm 1{ }^{\circ} \mathrm{C}$, durante 72 horas, em três repetições, conforme recomendações da ASAE (2000), método S352.2.

Condutividade elétrica: a condutividade elétrica da solução contendo soja foi medida, utilizando-se do "Sistema de copo" ou "Condutividade de massa" (VIEIRA et al., 2001).

Percentual de germinação: o teste-padrão do percentual de germinação foi feito de acordo com as Regras para Análise de Sementes (BRASIL, 1992). 
Massa específica aparente: usou-se massa limpa de cada amostra; a massa específica foi obtida utilizando-se de Balança de Peso Hectolitro de 1/4 de litro.

Teor de ácidos graxos livres: a determinação de ácidos graxos livres foi feita de acordo com as normas AOCS (1993), Método Ca 5a-40. O percentual de ácidos graxos livres (AGL), expressa em \% de ácido oleico, foi calculado por meio da eq. (1):

$$
\mathrm{AGL}=\frac{(\mathrm{Va}-\mathrm{Vb}) \mathrm{N} \text { f } 28,2}{\mathrm{~m}}
$$

em que,

$\mathrm{Va}$ - volume de $\mathrm{NaOH} 0,01 \mathrm{~N}$ gasto para a amostra, $\mathrm{mL}$;

$\mathrm{Vb}$ - volume de $\mathrm{NaOH} 0,01 \mathrm{~N}$ gasto para o branco, $\mathrm{mL}$;

$\mathrm{N}$ - normalidade da solução de $\mathrm{NaOH}$;

f - fator de correção da solução de $\mathrm{NaOH}$, e

$\mathrm{m}$ - massa da amostra, $\mathrm{g}$.

Índice de peróxido: a determinação do índice de peróxido foi realizada de acordo com as normas AOCS (1993), Método Cd 8-53. O índice de peróxido (IP) foi calculado por meio da eq.(2):

$$
\mathrm{IP}=\frac{(\mathrm{Va}-\mathrm{Vb}) \mathrm{N} \mathrm{f} 1000}{\mathrm{~m}}
$$

em que

IP - Índice de peróxido, meq $(\mathrm{kg} \text { de amostra })^{-1}$;

$\mathrm{Va}$ - volume de $\mathrm{Na}_{2} \mathrm{~S}_{2} \mathrm{O}_{3} 0,1 \mathrm{~N}$ padronizada gasto para na titulação da amostra, $\mathrm{mL}$;

$\mathrm{Vb}$ - volume de $\mathrm{Na}_{2} \mathrm{~S}_{2} \mathrm{O}_{3} 0,1 \mathrm{~N}$ padronizada gasto para na titulação do branco, $\mathrm{mL}$;

$\mathrm{N}$ - normalidade da solução de $\mathrm{Na}_{2} \mathrm{~S}_{2} \mathrm{O}_{3}$;

f - fator de correção da solução de $\mathrm{Na}_{2} \mathrm{~S}_{2} \mathrm{O}_{3}$, e

$\mathrm{m}$ - massa da amostra, $\mathrm{g}$.

\section{Delineamento experimental}

Utilizou-se do delineamento inteiramente casualizado para a soja úmida e seca, em esquema fatorial 4x3 (quatro períodos de armazenamento e três camadas do silo-bolsa), com três repetições. Foi realizado, inicialmente, o teste $\mathrm{F}$, a $5 \%$ de probabilidade, e a estatística descritiva para a apresentação dos resultados.

\section{RESULTADOS E DISCUSSÃO}

Os teores de água da soja armazenada com 17,4 e 13,4\% de teor de água mantiveram-se próximos aos valores observados no início do período de armazenamento, independentemente da camada do silo-bolsa (Figura 2). Comportamento semelhante foi observado por RODRIGUEZ et al. (2004) em grãos de milho úmidos e secos armazenados em silos tipo bolsa.

Os valores de condutividade elétrica da solução que continha soja com diferentes teores de água, ao longo do armazenamento, são apresentados na Figura 3. Observou-se aumento significativo da condutividade elétrica da soja com 17,4\% de teor de água (Figura 3A), em decorrência da interação entre camadas do silo tipo bolsa (superior, intermediária e inferior) e período de armazenamento, pelo teste $\mathrm{F}$, a $5 \%$ de probabilidade. O aumento ocorreu principalmente a partir do terceiro mês de armazenamento, e essa tendência foi observada nas três camadas do silo. Não foi verificada variação significativa desse parâmetro no material armazenado com 13,3\% de teor de água (Figura 3B) durante o período de armazenamento, indicando menor deterioração dos mesmos. É importante ressaltar que acréscimos nos valores de condutividade elétrica estão associados à maior deterioração da parede celular do produto, e um dos fatores que influenciam nesse comportamento é o seu teor de água (BURRIS, 1980). 

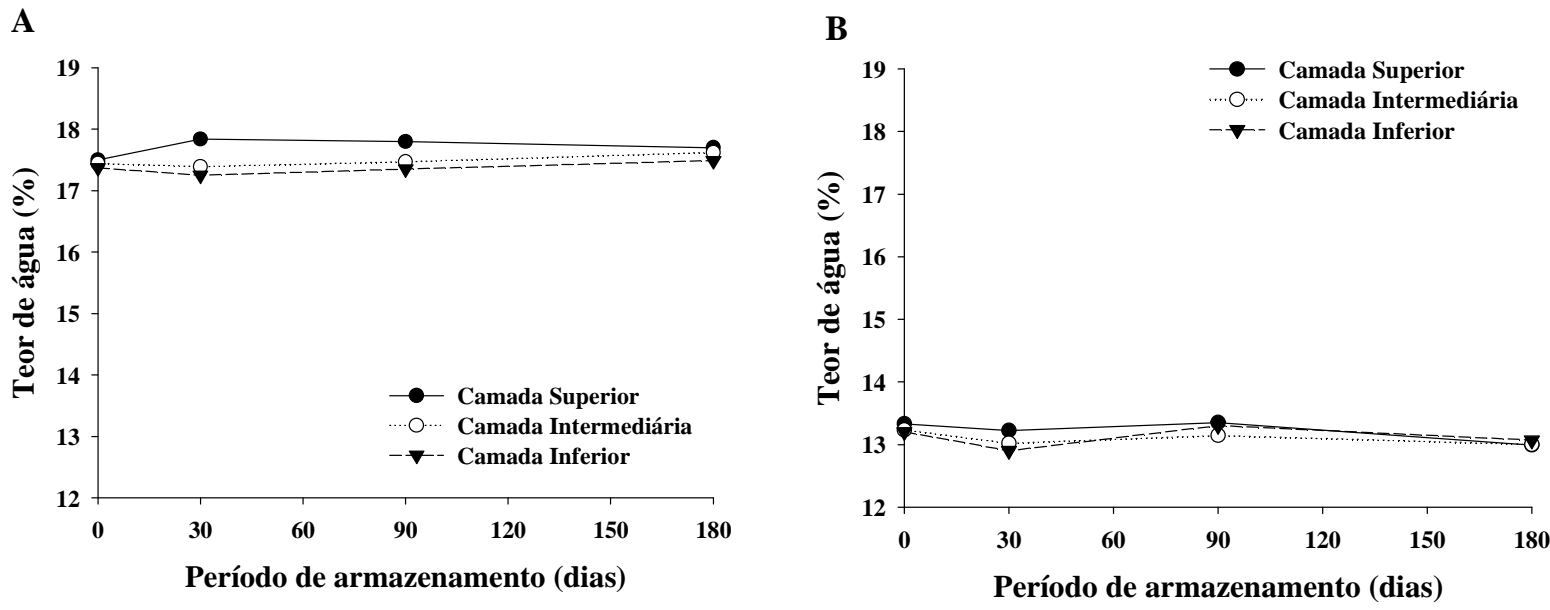

FIGURA 2. Valores médios de teor de água da soja armazenada em silos tipo bolsa durante 180 dias. Mean values of moisture content of soybean stored in bag type silos for 180 days.
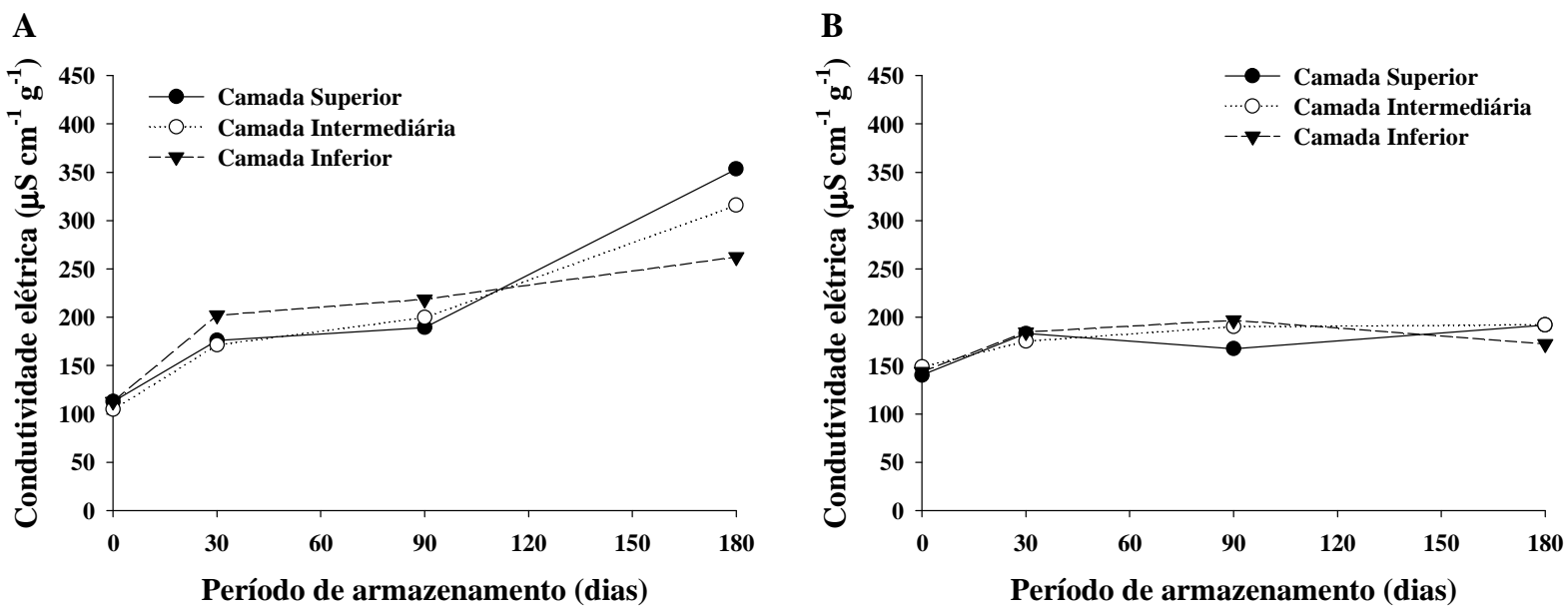

FIGURA 3. Valores médios de condutividade elétrica da soja armazenada com 17,4\% (A) e 13,3\% (B) de teor de água durante 180 dias. Mean values of electric conductivity of soybean stored with moisture content of $17.4 \%$ (A) and $13.3 \%$ (B) for 180 days.

$\mathrm{Na}$ Figura 4, são apresentados os valores médios do percentual de germinação de soja armazenada com 17,4 e 13,3\% de teor de água. A soja armazenada seca (Figura 4B) não apresentou decréscimo significativo desse parâmetro qualitativo. Entretanto, aquela armazenada úmida (Figura 4A) apresentou decréscimo significativo somente em decorrência do período de armazenamento, pelo teste $\mathrm{F}$, a $5 \%$ de probabilidade, independentemente da camada do silo. Esse comportamento do percentual de germinação da soja úmida foi mais acentuado a partir do terceiro mês, tendo sido obtido, após 180 dias, valor médio igual a 34\%. Os resultados são compatíveis com os de condutividade elétrica (Figuras 3A e 3B), ou seja, à medida que ocorre deterioração da parede celular das sementes, diminui o seu poder germinativo.

CASINI et al. (2006) realizaram estudo com grãos de trigo armazenados em silos tipo bolsa com teores de água de $12 \%, 14 \%$ e $16 \%$, temperatura entre $22{ }^{\circ} \mathrm{C}$ e $23{ }^{\circ} \mathrm{C}$, durante $60 ; 116 ; 136$ e 208 dias de armazenamento. Observaram que o percentual de germinação dos grãos de trigo armazenados com 94\% e teor de água de $12 \%$ foi mantido após 208 dias de armazenamento. Os grãos armazenados com 14\% e $16 \%$ de teor de água apresentaram, respectivamente, $62 \%$ e $3 \%$ de germinação após 208 dias de armazenamento. O percentual de germinação em grãos de milho úmidos e secos, armazenados por 153 dias em silos tipo bolsa, foi obtido por RODRIGUEZ et al. 
(2004). Esses autores obtiveram decréscimo do percentual de germinação de 89,0\% para 84,3\% nos grãos de milho armazenados com teor de água de 19,5\%. Entretanto, observaram maior decréscimo do percentual de germinação, de $68,9 \%$ para $57,3 \%$, nos grãos de milho armazenados com $14,8 \%$. Esse comportamento foi atribuído à temperatura mais elevada durante o período de armazenagem em comparação com os grãos armazenados com teor de água de 19,5\%.

A

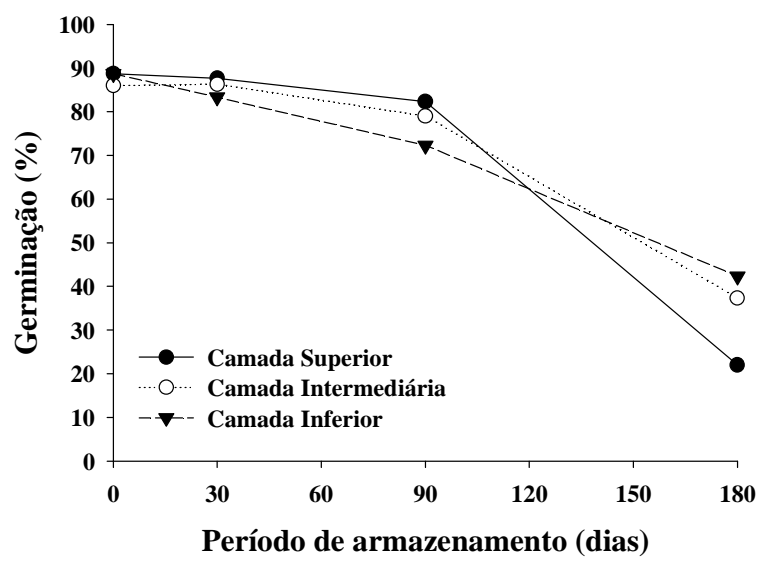

B

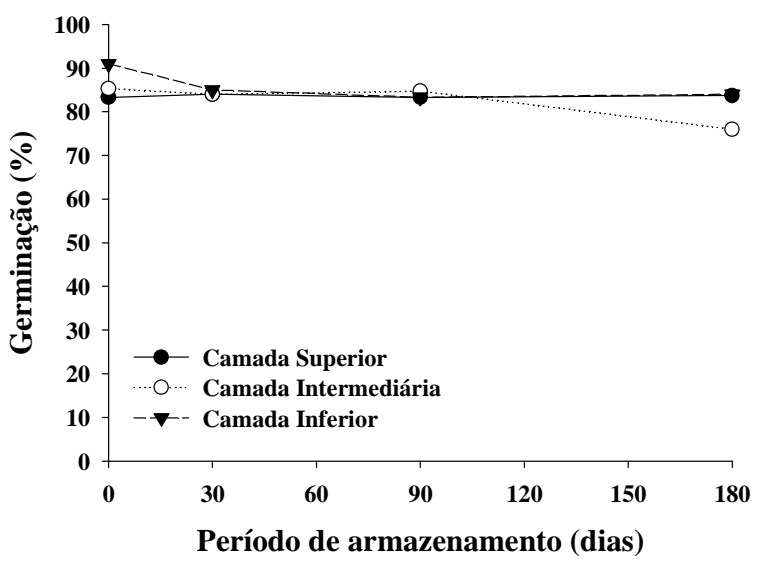

FIGURA 4. Valores médios de germinação da soja armazenada com 17,4\% (A) e 13,3\% (B) de teor de água durante 180 dias. Mean values of germination of soybean stored with moisture content of $17.4 \%$ (A) and $13.3 \%$ (B) for 180 days.

Com relação à massa específica aparente da soja armazenada com 17,4\% (Figura 5A) e com 13,3\% (Figura 5B) de teor de água, não foi verificada variação significativa ao longo do período de armazenamento, pelo teste $\mathrm{F}$, a $5 \%$ de probabilidade. É bom salientar que, mesmo a massa específica aparente não sendo um parâmetro utilizado na comercialização da soja, redução desse parâmetro pode estar associada à perda de qualidade do produto em consequência dos processos de deterioração durante o armazenamento e, consequentemente, à perda de qualidade (SILVA, 1997). Esse autor afirmou, ainda, que baixos valores de massa específica são encontrados em grãos que perderam, excessivamente, matéria seca devido à infestação de fungos e/ou insetos no campo e/ou no armazenamento.
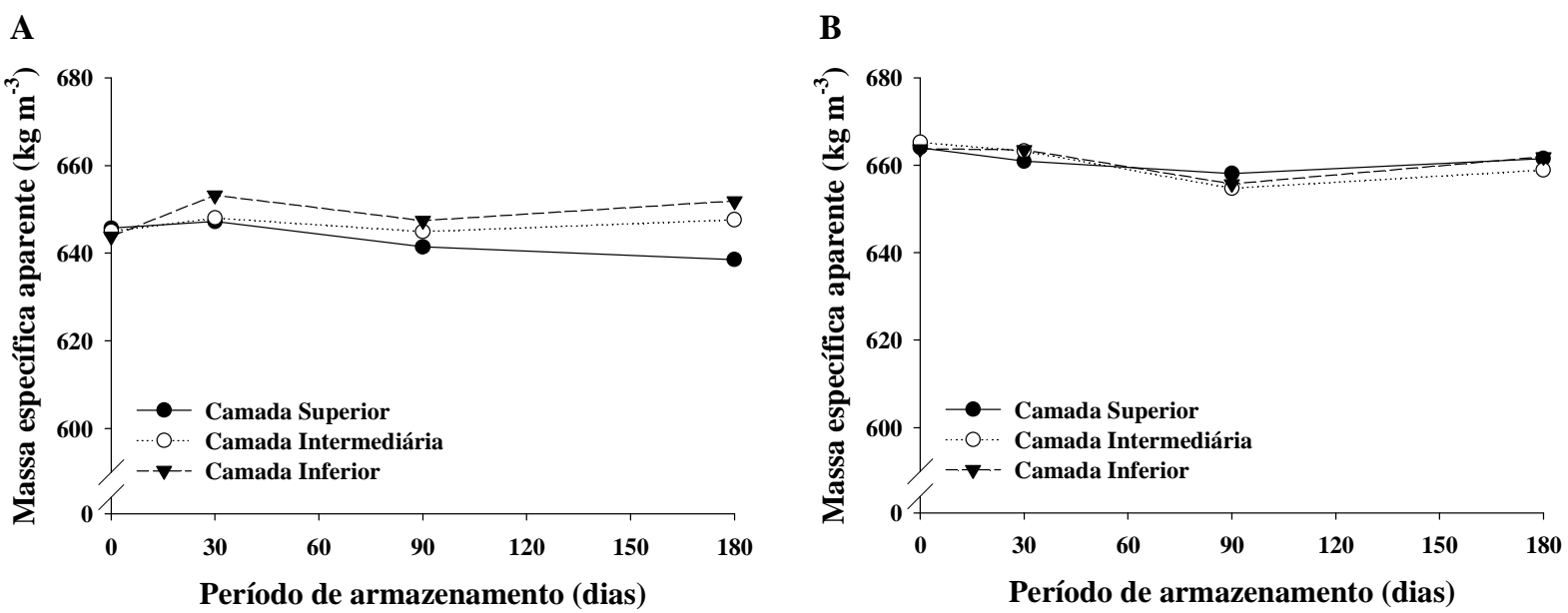

FIGURA 5. Valores médios de massa específica aparente da soja armazenada com $17,4 \%$ (A) e $13,3 \%$ (B) de teor de água durante 180 dias. Mean values of apparent specific grain mass of soybean stored with moisture content of $17.4 \%$ (A) and $13.3 \%$ (B) for 180 days. 
Os valores médios do teor de ácidos graxos livres do óleo bruto extraído de soja armazenada com 17,4 e 13,3\% de teor de água, nas três camadas do silo tipo bolsa, são apresentados na Figura 6. Verificou-se que esse parâmetro não apresentou variações ao longo do armazenamento. Observou-se, também, que o teor de ácidos graxos livres, tanto para o óleo bruto extraído da soja armazenada úmida quanto seca, manteve-se abaixo do limite estabelecido pela ANVISA (1999), de $2 \%$, para comercialização de óleo bruto de soja. Os valores correspondentes ao óleo bruto extraído de soja úmida e seca após 180 dias foram de $1,05 \%$ e $0,59 \%$, respectivamente. RODRIGUEZ et al. (2006) avaliaram a qualidade de girassol armazenado em silos-bolsa e verificaram que o produto armazenado com teor de água de 8,4\% apresentou aumento significativo do teor de ácidos graxos livres após 160 dias, embora abaixo do limite exigido para comercialização. O girassol, armazenado com teor de água de 16,4\%, apresentou teor de ácidos graxos livres acima do limite, após 160 dias de armazenamento.

É importante mencionar que os óleos de origem vegetal podem apresentar valores de ácidos graxos livres relativamente altos, caso o produto apresente danos procedentes do campo ou de práticas incorretas de armazenagem. Esses altos valores podem ocasionar perdas excessivas no refino (O'BRIEN, 2004). WILSON et al. (1995) afirmaram que perdas no refino entre $1 \%$ e 1,5\% são consideradas normais. Mas tais perdas podem chegar a $4 \%$ ou mais, à medida que ocorrerem valores mais altos de ácidos graxos livres. $\mathrm{O}$ aumento de ácidos graxos livres dos lipídios ocorre pela ação de enzimas lipases e fosfolipases presentes no próprio material ou produzidas pela microflora associada que contribui para o rompimento das ligações éster dos triglicerídios (ZADERNOWSKI et al., 1999).

A

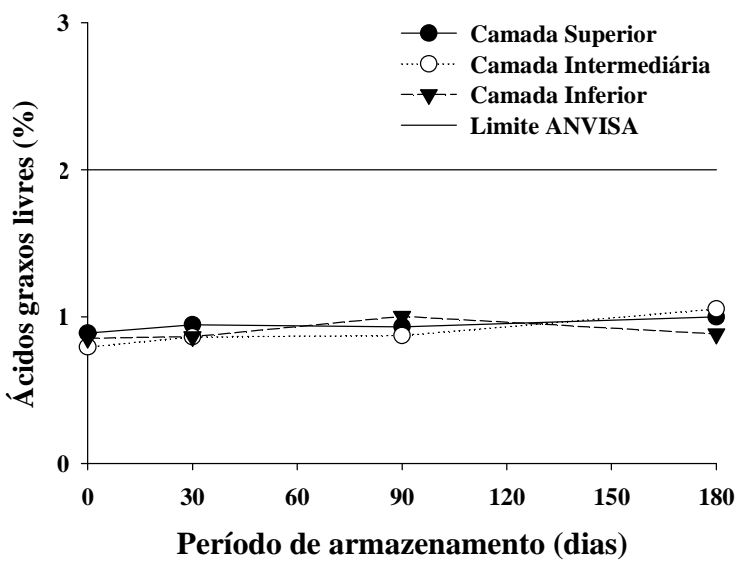

B

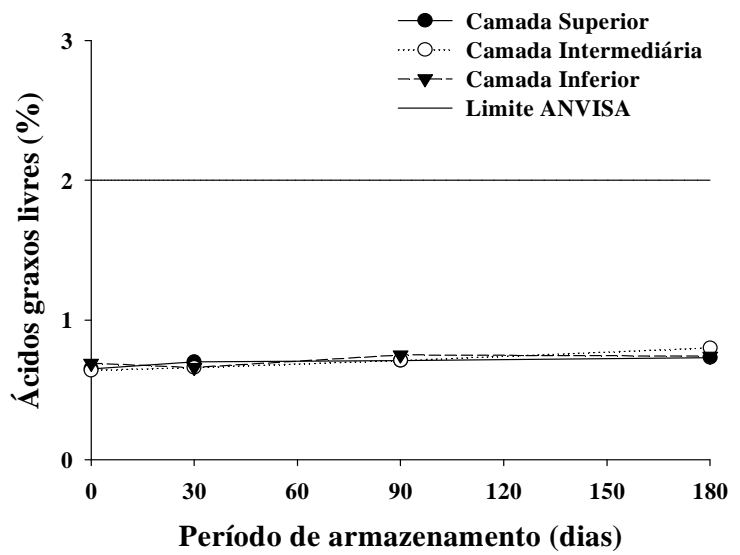

FIGURA 6. Valores médios de ácidos graxos livres (\%) do óleo bruto extraído de soja armazenada com $17,4 \%$ (A) e 13,3\% (B) de teor de água durante 180 dias. Mean values of free fatty acids (\%) in crude oils from soybean stored with moisture content of $\mathbf{1 7 . 4 \%}$ (A) and $13.3 \%$ (B) for 180 days.

Na Figura 7, estão os valores médios de índice de peróxidos (meq $\mathrm{kg}^{-1}$ de amostra) do óleo bruto extraído de soja armazenada úmida e seca. Verificou-se comportamento semelhante em relação ao percentual de ácidos graxos livres. Destaca-se que, ao longo dos 180 dias de armazenamento, os valores médios do índice de peróxidos para ambos os casos apresentaram-se abaixo do limite de 10 meq kg${ }^{-1}$ de amostra, estabelecido pela ANVISA (1999) para a comercialização do óleo bruto de soja.

Embora os peróxidos não apresentem nem sabor nem odor, são rapidamente decompostos, mesmo sob temperatura ambiente, em aldeídos, cetonas, álcoois, hidrocarbonetos, ésteres, furanos e lactonas, ocasionando sabor e odor desagradáveis nos óleos e gorduras (EYS et al., 2004; O'BRIEN, 2004). HOU \& CHANG (2004) afirmaram que o aparecimento de off-flavors, aroma e sabor desagradáveis em derivados de soja, pode ser parcialmente atribuído à peroxidação de lipídios. 
Outras consequências da oxidação lipídica nos alimentos são as alterações no valor nutricional, na funcionalidade e também na integridade e na segurança do produto, por meio da formação de compostos poliméricos potencialmente tóxicos (SILVA et al., 1999; NAZ et al., 2004; RAMALHO \& JORGE, 2006).
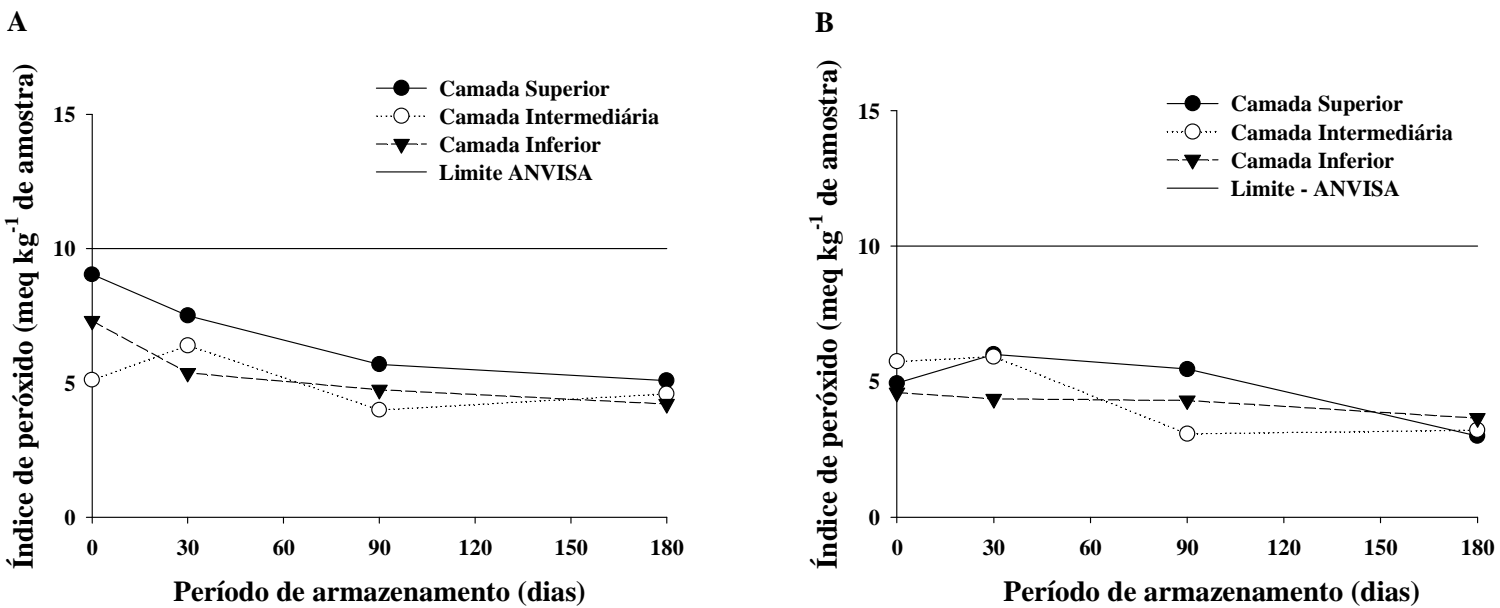

FIGURA 7. Valores médios de índice de peróxido (meq $\mathrm{kg}^{-1}$ ) do óleo bruto extraído de soja armazenada com 17,4\% (A) e 13,3\% (B) de teor de água durante 180 dias. Mean values of peroxide value index (meq $\mathrm{kg}^{-1}$ ) in crude oils from soybean stored with moisture content of $17.4 \%$ (A) and $13.3 \%$ (B) for 180 days.

\section{CONCLUSÕES}

A partir dos resultados obtidos, pode-se concluir que os silos tipo bolsa são uma alternativa viável do ponto de vista qualitativo para armazenagem de soja, e o armazenamento nesse tipo de estrutura não ocasiona alterações qualitativas no óleo bruto obtido a partir de soja armazenada seca e úmida, em condições similares àquelas deste estudo.

\section{REFERÊNCIAS}

ANVISA. Agência Nacional de Vigilância Sanitária. Resolução no 482 de 23 de setembro de 1999. Disponível em: <http://www.anvisa.gov.br/legis/resol/482_99.htm>. Acesso em: 28 dez. 2006

AOCS. Official methods and recommended practices of the American Oil Chemists' Society. $2^{\text {nd }}$ ed. Champaign, 1993. $1.200 \mathrm{p}$.

ASAE. American Society of Agricultural Engineering. Moisture measurement - unground grain and seeds. In:__ASAE Standards. 47. ed. St. Joseph: ASAE, 2000. p.563.

BRASIL. Ministério da Agricultura Pecuária e Abastecimento. Regras para análise de sementes. Brasília, 1992. 365 p.

BURRIS, J.S. Maintenance of soybean seed quality in storage as influenced by moisture, temperature and genotype. Iowa State Journal of Research, Ames, v.54, p.377-379, abr./jun. 1980.

CASINI, C.; BRAGACHINI, M.; CUNIBERTI, M. Ensayo de simulación de almacenamiento de trigo en silo "Bag". INTA EEA Manfredi. Disponível em:

<http://www.inta.gov.ar/bn/ph/info/documentos/res16.htm.> Acesso em: 10 abr. 2006.

COUTO, S.M.; SILVA, M.A.; REGAZZI, A.J. An electrical conductivity method suitable for quantitative mechanical damage evaluation. Transactions of the ASAE, St. Joseph, v.41, n.2, p.421426, 1998. 
DHINGRA, O.D.; JHAM, G.; NAPOLEÃO, I.T. Ergosterol accumulation and oil quality changes in stored soybean invaded by Aspergillus ruber (A. glaucus group). Mycopathologia, Springer, v.143, p.85-91, ago. 1998.

EYS, J.E.; OFFNER, A.; BACH, A. Manual of quality analyses for soybean products in the feed industry. Fourqueux: ASA, 2004. 115 p.

FRANKEL, E.N.; NASH, A.M.; SNYDER, J.M. A methodology study to evaluate quality of soybeans stored at different moisture levels. Journal of the American Oil Chemists' Society, Champaign, v.64, n.7, p.987-992, 1987.

HOU, H.J.; CHANG, K.C. Storage conditions affect soybean color, chemical composition and tofu qualities. Journal of Food Processing and Preservation, Westport, v.28, p.473-488, nov./dez. 2004.

JAYAS, D. Controlling insects in stored grain using modified atmospheres of elevated carbon dioxide. L'Actualité chimique canadienne. Ottawa, v.52, n.7, p.10-24, 2000.

MORENO, M.E.; JIMENEZ, A.S.; VAZQUEZ, M.E. Effect of Sitophilus zeamais and Aspergillus chevalieri on the oxygen level in maize stored hemetically. Journal Stored Product Research, Oxford, v.36, p.25-36, jan./mar. 2000.

MORENO, M.E.; JIMENEZ, A.S.; VAZQUEZ, M.E. Hermetic storage system preventing the proliferation of Prostephanus truncatus Horn and storage fungi in maize with different moisture contents. Postharvest Biology and Technology, Pullman, v.39, p.321-326, 2006.

NARAYAN, R.; CHAUHAN, G.S.; VERMA, N.S. Changes in the quality of soybean during storage. Part 2 - Effect of soybean storage on the sensory qualities of the products made therefrom. Food Chemistry, Oxford, v.30, p.181-190, jul./set. 1988.

NAZ, S.; SHEIKH, H.; SIDDIQI, R.; SAYEED, S.A. Oxidative stability of olive, corn and soybean oil under different conditions. Food Chemistry, Oxford, v.88, p.253-259, nov. 2004.

O'BRIEN, R.D. Fat an oils. In: O'BRIEN, R.D. (Ed.). Fats and oils formulating and processing for applications. Boca Raton: CRC Press, 2004. p.175-232.

RAMALHO, V.C.; JORGE, N. Antioxidantes utilizados em óleos, gorduras e alimentos gordurosos. Química Nova, São Paulo, v.29, n.4, p.755-760, jul./ago. 2006.

REGITANO-D'ARCE, M.A.B.; RAUENMIGUEL, A.M.O.; CASAGRANDE, J.R.R.; MARCOS, E.A.; PLONIS, G. Time of harvesting and storage of soybeans - influence on oil quality. Grasas $Y$ Aceites, Sevilla, v.45, n.4, p.237-240, 1994.

RODRIGUEZ, J.C.; BARTOSIK, R.E.; MALINARICH, H.D.; EXILART, J.P.; NOLASCO, M.E. IP short time storage of Argentine cereals in silobags to prevent spoilage and insect. In:

INTERNATIONAL QUALITY GRAINS CONFERENCE, 2004, Indianapolis. Proceedings... West Lafayette: Purdue University, 2004. 1-15.

RODRIGUEZ, J.C.; BARTOSIK, R.E.; MALINARICH, H.D.; EXILART, J.P.; NOLASCO, M.E. Almacenaje de granos en bolsas plásticas: sistema silobag. EEA INTA Balcarce. Disponível em: $<$ http://www.inta.gov.ar/balcarce/info/documentos/agric/posco/granos/silobag.htm>. Acesso em: 30 jun. 2006.

RUPOLLO, G.; GUTKOSKI, L.C.; MARTINS, I.R.; ELIAS, M.C. Efeito da umidade e do período de armazenamento hermético na contaminação natural por fungos e a produção de micotoxinas em grãos de aveia. Ciências Agrotécnicas, Lavras, v.30, n.1, p.118-125, 2006.

SILVA, A.A.L. Influência do processo de colheita na qualidade do milho (Zea mays L.) durante o armazenamento. 1997. 77 f. Dissertação (Mestrado em Pré-processamento e Armazenamento de Produtos Agrícolas) - Universidade Federal de Viçosa, Viçosa, 1997. 
SILVA, F.A.M.; BORGES, M.F.M.; FERREIRA, M.A. Métodos para avaliação do grau de oxidação lipídica e da capacidade antioxidante. Química Nova, São Paulo, v.22, n.1, p.94-103, 1999.

VARNAVA, A.; NAVARRO, S.; DONAHAYE, E.Long-term hermetic storage of barley in PVCcovered concrete platforms under Mediterranean conditions. Postharvest Biology and Technology, Pullman, v.6, p.177-186, 1995.

VIEIRA, R.D.; TEKRONY, D.M.; EGLI, D.B.; RUCKER, M. Electrical conductivity of soybean seeds after storage in several environments. Seed Science and Technology, Zurich, v.29, p.599-608, out. 2001.

VILLERS, P.; BRUIN, T.; NAVARRO, S. Safe storage of grain in the tropics: A comparison of hermetic storage in flexible silos versus rigid metal or concrete silos. In: WEST, A.; BROWN, J. (Eds.) Feed technology update. Honolulu: Linx Publishing, 2006, p.17-22.

WILSON, R.F.; NOVITZKY, W.P.; FENNER, G.P. Effect of fungal damage on seed composition and quality of soybeans. Journal of the American Oil Chemists' Society, Champaign, v.72, n.12, p.1.425-1.429, 1995.

ZADERNOWSKI, R.; NOWAK-POLAKOWSKA, H.; RASHED, A.A. The influence of heat treatament on the activity of lipo and hydrophilic components of oat grain. Journal of Food Processing and Preservation, Westport, v.33, p.177-191, set. 1999. 